\title{
SOME THOUGHTS ON EARLY DETECTION AND INTERVENTION IN DIABETES MELLITUS
}

\author{
Victor M. Hawthorne and Catherine C. Cowie \\ Department of Epidemiology, The University of Michigan, School of Public Health, Ann Arbor, \\ MI 48109, U.S.A.
}

(Received 29 November 1983)

DESPITE the fact that a casual plasma glucose $<200 \mathrm{mg} / \mathrm{dl}$ or a fasting plasma glucose $>140 \mathrm{mg} / \mathrm{dl}$ on more than one occasion; or a casual blood sugar $<140 \mathrm{mg} / \mathrm{dl}$ or fasting values $<100 \mathrm{mg} / \mathrm{dl}$ respectively either establishes or reputedly excludes a diagnosis of diabetes [1]; and that both impaired glucose tolerance (IGT) and diabetes appear to meet as many of the criteria for mass screening as hypertension [2], there has been no return to the enthusiasms of the late sixties and early seventies for campaigns of detection and early intervention in the general population. The reasons are not hard to seek. Historically diabetologists were foremost in protesting the long queues of volunteer participants referred from screening surveys to their outpatient clinics as dipstick positive for sugar in the urine or in the blood, and largely negative at follow-up. Predictive values of 28 and sometimes as low as $14 \%$ did much to discredit screening in those early days. Then paradoxically, although it was agreed that coronary heart disease in Western cultures was three times as prevalent in diabetic males and six times as prevalent in diabetic females than in corresponding non-diabetics [3], the view in Great Britain was that about 1 or $2 \%$ of the general population was diabetic, treatment did not radically alter the outcome, so why deviate resources to case detection?

Subsequent experience seems to have borne out the wisdom of this view. As far as coronary heart disease is concerned, an extensive review of the results of 14 longitudinal studies in nine countries, of the relationship of asymptomatic hyperglycemia to coronary heart disease, did not reveal an association that was consistent, strong and graded [4]. It was concluded that asymptomatic hyperglycemia could not be designated an established risk factor for coronary heart disease and the major adult cardiovascular diseases. Thus there seems to be a consensus that with the exception of pregnancy, evidence is lacking that early detection and intervention are beneficial to the majority of undiagnosed diabetics in preventing either complications or mortality [5].

But old enthusiasms die hard. Perhaps in the light of insufficient evidence, especially in the absence of positive contradictory findings, we should give the old Scottish legal verdict of "not proven"; and our College should move towards renewing interest and endorsing support for further studies of early asymptomatic diabetes and IGT in the general population. The point has been made that both non-insulin dependent diabetes mellitus (NIDDM) and, more recently, most insulin dependent diabetes mellitus (IDDM) patients, pass through a phase of varying but often of substantial duration, in which IGT is present. Even if not all IGT patients proceed to diabetes, this is a familiar epidemiological situation which would seem to have excellent experimental potential for prevention.

IDDM may have more appeal for the clinician than the epidemiologist but the presence of islet cell (cytoplastic) antibodies at diagnosis of IDDM [G] has potential for even earlier diagnoses. The presence of IGT in some children for periods extending up to three years, 
suggests a useful lead time which could be exploited experimentally. Perhaps it is too early yet for those with a communicable disease orientation to get excited about viruses and vaccines but the low prevalence of IDDM and the prospect of randomized controlled trials of the effects of cyclosporin on the immunological process of beta cell destruction suggests inter-disciplinary collaboration and randomized controlled trials of prevention.

The recent report of the effects of early, aggressive, antihypertensive treatment in reducing the rate of decline in kidney function in diabetic nephropathy [7], indeed the growing interest of a multifactorial role for hypertension in contributing to the complications of diabetes, if not to the control of diabetes itself, prompted examination of some preliminary results of a pilot chart review study which divided 43 IDDM patients into three groups: 15 IDDM patients in End Stage Renal Disease (ESRD), 14 non-diabetic ESRD patients and $14 \mathrm{IDDM}$ patients not in ESRD. Patients were matched by sex and race, ESRD patients by age at onset of ESRD, and diabetic non ESRD controls by duration of diabetes.

As might be expected, and Table 1 shows, mean systolic and diastolic blood pressures were markedly higher for both ESRD groups compared with the non-ESRD diabetics; but whereas there was a slight reduction in mean systolic and diastolic blood pressure between the first and final year of observation for the non-diabetic ESRDs, blood pressure rose consistently and markedly for the diabetic ESRDs. These preliminary results seem to underline the value of collective chart review in providing perspective for clinical findings in individual patients; and, if confirmed in a larger series, would emphasize the need for a more aggressive approach to control of hypertension in preventing diabetic complications. It would then be interesting to speculate whether the hypoglycemic effects of $\beta$-adrenergic blocking drugs might be preferred to the hyperglycemic propensities of the thiazides for trials of hypertension with concomitant diabetes or preferably, IGT. In the same area of speculation, the long term predictive value for ESRD of albumin excretion in excess of $40 \mathrm{mg}$ per day [8] might suggest microalbuminaria as another associated condition enhancing the need for the more intensive treatment of hypertension concomitant with diabetes.

NIDDM has a prevalence more consonant with the criteria for screening [2]; and the association of the same condition with obesity enlarges the potential for evaluating prevention in large scale epidemiological studies. Experience in the Tecumseh Study has highlighted the importance of adiposity as a remediable characteristic of diabetes [9]. Restriction to an older age group, high levels of undiagnosed disease in the general population, and the fact that decreased insulin action in NIDDM patients can apparently be reversed by weight control or weight loss [10], all seem to support the wisdom of a return to epidemiologic trials of preventive measures involving screening of defined populations.

Just as it was tempting, and in many ways efficacious, to apply experience and methods gained in the control of tuberculosis, to the control of coronary heart disease and stroke, so now it is of interest to look for analogies in experience and methods in the control of cardiovascular disease which might be applicable to the control of diabetes.

In NIDDM the non-responsiveness of endogenous insulin secretion to the stimulus of glucose and of impaired insulin secretion to non-glucose stimuli like tolbutamide, together with the need to reduce ambient glucose levels for prolonged periods in the face of a high

\begin{tabular}{|c|c|c|c|c|}
\hline & \multirow[b]{2}{*}{$N$} & \multirow[b]{2}{*}{ First year } & \multicolumn{2}{|c|}{ Observation year } \\
\hline & & & Middle year & Last year \\
\hline \multicolumn{5}{|l|}{ Systolic } \\
\hline Diabetic ESRD & 15 & $128.72 \pm 17.39$ & $153.97 \pm 17.21$ & $173.27 \pm 27.04$ \\
\hline Non-diabelic ESRD & 14 & $154.25 \pm 18.86$ & $141.31 \pm 19.18$ & $151.42 \pm 23.91$ \\
\hline Diabetic & 14 & $121.06 \pm 16.99$ & $130.47 \pm 17.58$ & $130.00 \pm 18.53$ \\
\hline \multicolumn{5}{|l|}{ Diastolic } \\
\hline Diabetic ESRD & 15 & $86.17 \pm 8.45$ & $100.51 \pm 11.78$ & $105.86 \pm 13.62$ \\
\hline Non-diabetic ESKU & 14 & $98.30 \pm 2.73$ & $91.56 \pm 10.66$ & $95.85 \pm 18.10$ \\
\hline Diabetic & 14 & $78.07 \pm 14.56$ & $85.82 \pm 13.00$ & $84.68 \pm 12.59$ \\
\hline
\end{tabular}


degree of insulin resistance, is one such instance. Could recent developments in our understanding of the control of cholesterol (where a combination of genetic and microbiological knowledge of the mechanism of lipid metabolism has indicated the probability that a two-drug regime may be needed to lower the lipid level sufficiently, to make a difference in disease risk) point to the existence of a similar model and the need for similar integrative knowledge in diabetes [11]? More widely, could not the advantages of reducing the complications of diabetes by lowering multiple small risks, as represented by the population mean blood pressure level by a few $\mathrm{mmHg}$, or in cholesterol or blood glucose by a few $\mathrm{mg} / \mathrm{dl}$, compared with reduction of a small number of large risks in patients with established disease? The strategy now seems clearly established for hypertension [12] and hypercholesterolemia [13] in the causation of coronary heart disease. Could it not now be tried for diabetes? Reduction in population levels of blood glucose and obesity by dietary methods would seem to suggest themselves as the best candidates for early trials. Perhaps there is already a natural experiment in progress in this country, but is there an adequate health information system in place to measure change? It would seem imperative that in endorsing a high priority for trials of reducing obesity by changing physical activity and through quantitative and qualitative changes in diet in high risk sub-groups, the desirability of encouraging smaller and perhaps more achievable reductions of risk in larger numbers of the apparently healthy population through health education and even screening for high risk, should not be overlooked. In this regard screening for gestational diabetes is no longer controversial [14]. Perhaps a start might be made to deal with the dearth of evaluative studies whose results might illuminate some of the doubts surrounding benefits of screening other high risk and general populations for diabetes?

Acknowledgements - Support for the study of diabetes in end-stage renal disease was provided by a grant from the Michigan Department of Public Health.

\section{REFERENCES}

1. WHO Expert Committee on Diabetes Mellitus: WHO Tech Rep Ser 646, 2nd report. Geneva: World Health Organization, 1980

2. Wilson JGM, Jungner G: Principles and Practice of Screening for Disease. Geneva: World Health Organization, 1968

3. Report of a Joint Working Party of the Royal College of Physicians of London and the British Cardiac Society: J R Coll Physicians London 10: 1-63, 1976

4. The International Collaborative Group: Joint discussion on asymptomatic hyperglycemia and coronary heart disease. J Chron Dis 32: 829-837, 1979

5. Bennett PH: Early detection and intervention in diabetes mellitus-Is it effective? Proc Am Coll Epid Sep. 22, 1983

6. Lendrum R, Walker G, Gamble DR: Islet-cell antibodies in juvenile diabetes mellitus of recent onset. Lancet 1: $880-882,1975$

7. Parving $\mathrm{HH}$, Andersen AR, Smidt $\mathrm{U}$, and Svendsen PA: Early aggressive antihypertensive treatment reduces rate of decline in kidney function in diabetic nephropathy. Lancet 1: 1175-1179, 1983

8. Virberti GC, Hill RD, Jarrett RI, Argyropoulos A, Mahmud V, Keen H: Microalbuminuria as a predictor of clinical nephropathy in insulin-dependent diabetes mellitus. Lancet 1: 1430-1432, 1982

9. Butler WJ, Ostrander LD Jr, Carman WJ, Lamphiear DE: Diabetes mellitus in Tecumseh, Michigan. Am J Epid 116: 971-980, 1982

10. Report of the National Diabetes Advisory Board: Diabetes - the Continuing Challenge. US Department of Health and Human Service, Public Health Service, National Institutes of Health, NIH Publication No. 83-2624, 1983

11. Kolata G: Cholesterol-heart disease link illuminated. Science 221: 164-1166, 1983

12. Hawthorne VM, Beevers DG, Gilmour H, Stewart GM, Watt H: Effectiveness of screening for hypertension in Scotland. Clin Sci Mol Med S1: 653s-656s, 1976

13. Hawthorne VM: Diet and coronary heart disease. Br Med J 2: 186-187, 1977

14. Proc American Diabetes Association Workshop on Gestational Diabetes: Summary and recommendations. Diabetes Care Vol 3: 499-501, 1980 